\title{
A Participatory Co-creation Model to Drive Community Engagement in Rural Indigenous Schools: A Case Study in Sarawak
}

\author{
Jacey-Lynn Minoi ${ }^{1}$, Fitri Mohamad ${ }^{1}$, Sylvester Arnab ${ }^{2}$, John Phoa, L. Morini ${ }^{2}$, J. Beaufoy ${ }^{2}$, T. \\ $\mathrm{Lim}^{1}$, and S. Clarke ${ }^{2}$ \\ ${ }^{1}$ Social Informatics and Technological Innovations, Universiti Malaysia Sarawak, Malaysia \\ ${ }^{2}$ Coventry University, UK \\ jacey@unimas.my \\ mfitri@unimas.my \\ S.Arnab@coventry.ac.uk \\ iphoacl@gmail.com \\ ac2009@coventry.ac.uk \\ adx984@coventry.ac.uk \\ terrin@unimas.my \\ ab4588@coventry.ac.uk \\ DOI: 10.34190/JEL.17.3.001
}

\begin{abstract}
This paper presents the formulated 'play-to-engage' model for indigenous community engagement that incorporates factors in cultural protocols and game design thinking. The hybrid model of the participatory co-creation model was formulated in the study that had been rolled out in two rural primary schools in West Borneo. These schools are located in remote villages, away from urban amenities, and technological affordances and resources are limited. There are more than twenty culturally-diversed indigenous tribes in Borneo. Although it is a known fact that indigenous cultures, including those in Borneo, have many cultural protocols and distinctive custom practices, it is still a challenge for researchers who work with such communities to understand, adhere to and follow the cultural protocols. The model looks at incorporating gameplay and culture protocols to drive community engagement. Since play is universal, the creation of a trustworthy partnership between the community and researchers was established through the use of play during the engagement process. Narratives captured in the study represented reflection, problem solving and creativity in the interactions with the indigenous communities, based on the developed indicators of the 'play-to-engage' model.
\end{abstract}

Keywords: play-to-engage, participatory co-creation, indigenous community engagement, culture

\section{Introduction}

Social research and intervention associated to the communities in Asia, in particular the indigenous rural communities, pose a challenge in terms of the need to be more empathetic and aware of the cultures that are very diverse, especially when the research and intervention approach is based on Western contexts. There is a need to be a more holistic and pragmatic pathway for ensuring that we are sensitive to the context of the communities in order to build trust and positive partnership.

One methodology to address the social inequity outsider researchers and indigenous peoples communities is the participatory action research (PAR). The participatory action research approach to community issues is a culturally relevant and empowering method for indigenous people in Canada and worldwide as it critiques the ongoing impact of colonisation, neocolonialism and the force of marginalisation (Severtson, Bauman, \& Will, 2002). Participatory action research gives a voice to the oppressed and marginalised, and the methods and processes promote empowerment, inclusivity, and respect (Dickson \& Green, 2001). Most importantly, this approach serves to deconstruct the Western positivist research paradigm that is, and has always been, antithetical to indigenous ways of coming to knowledge on many levels; theoretically, cognitively, practically, and spiritually (Haig-Brown \& Dannenmann, 2000). PAR can, therefore, be quite significant to the inclusion of indigenous epistemology in the discourse of research.

Much of the literature about indigenous community engagement centres around the "connections between two bodies of critical scholarship - Eurocentrism and Whiteness (Madden, Higgins and Korteweg, 2013)". Madden et al. addressed the nature of community engagement on indigenous communities in Borneo, where

Reference this paper: Minoi, J.L., et al., 2019 A Participatory Co-creation Model to Drive Community Engagement in Rural Indigenous Schools: A Case Study in Sarawak. The Electronic Journal of e-Learning, 17(3), pp. 173-183, available online at www.ejel.org 
they emphasised that community involvement requires new skills, new knowledge and new approaches to interpret narratives and situations within an indigenous community. There have been many undocumented cases where external actors often do not understand the indigenous community's customary protocols and governance systems because they are codified in ways specific to each community, culture, and location.

Failing to respect community protocols and customs, whether intentional or not, can lead to conflict, deterioration of otherwise constructive relations, and consequently negative impacts on the environment.

The article, therefore, provides insights into an action research, which was conducted around the engagement with such rural communities, centred around the use of playful approaches. Acknowledging that play is common to all cultures and is highly universal, we constructed a 'play-to-engage' model based on the concept of design thinking taking into account the specific cultural protocols and incorporating community empowerment indicators for indigenous schools and their respective villages. The direct output from the model is a participatory co-creation approach based on the 'play-to-engage' model to drive community engagement to guide researchers who are unfamiliar with indigenous communities and their unique cultural protocols.

As part of the co-creative process, the model integrates elements of game design and design thinking into an approach (i.e. in Arnab et al. (2017)'s Game Design Thinking) which enables the creation of new ideas and solving of complex problems. The benefit of design thinking for community engagement allows people to think and design their future, using their ingenuity and locally available resources (Burkett, 2016). Once the community is onboarded, practice building based on this co-creativity approach can be carried out. This model is relevant for other researchers and developers that will ensure positive engagement is achieved before any intervention can be implemented.

The article further elaborates on the 'play-to-engage' model, discussing its engagement pathway from onboarding through to co-creativity that supports learning. The onboarding process demonstrates the cultural protocol that involves getting the community onboard prior to engaging with the young people at the local schools. Section 3 discusses the constructed and identified indicators, and the outcomes of the engagement based on the indicators are analysed and presented in section 4. Finally, the results are concluded in section 5.

\section{Play-to-Engage model - method and materials}

This section discussed the engagement pathway underpinned by the 'play-to-engage' model implemented by the team associated to the Newton Funded CreativeCulture project (http://mycapsule.my) - a project that is aiming to introduce creative and playful pedagogy for teachers and learners in the rural Borneo. This project acknowledges the fact that rural communities around the world are marginalised due to lack of access to quality and also aligns with the emphasis on play as a key instrument for equipping young people with the skills to address and embrace the new realities of tomorrow (Brodin et al., 2019). Brodin et al. has also identified an alarming gap in play by gender and socio-economic factors for children across 70 countries, highlighting a strong link between play and the development of a range of skills children will need to flourish in the realities posed by Globalisation 4.0.

With these perpectives and contexts, the 'play-to-engage' model is informed by the playful Game Design Thinking, the communities themselves and their cultural protocols associated to the indigeneous communities.

\subsection{Game Design Thinking}

Game design thinking is based on design thinking, where it involves the use of play and gameplay (Arnab et al. 2017 ) in the design process. We adopted game design thinking in the study to test how game elements can be integrated to enhance community engagement. Games use strategies and mechanics (how to play the game), teamwork (working together as a team) and problem management (how to solve the problems and to find innovative solutions). Applying game design thinking to our project led us to focus on understanding user's point of view, and in the case of the study, the indigenous community.

Figure 1 presents game design thinking with play and games inspirations that consists of five main steps, namely Empathise, Define, Ideate, Prototype, and Test. 


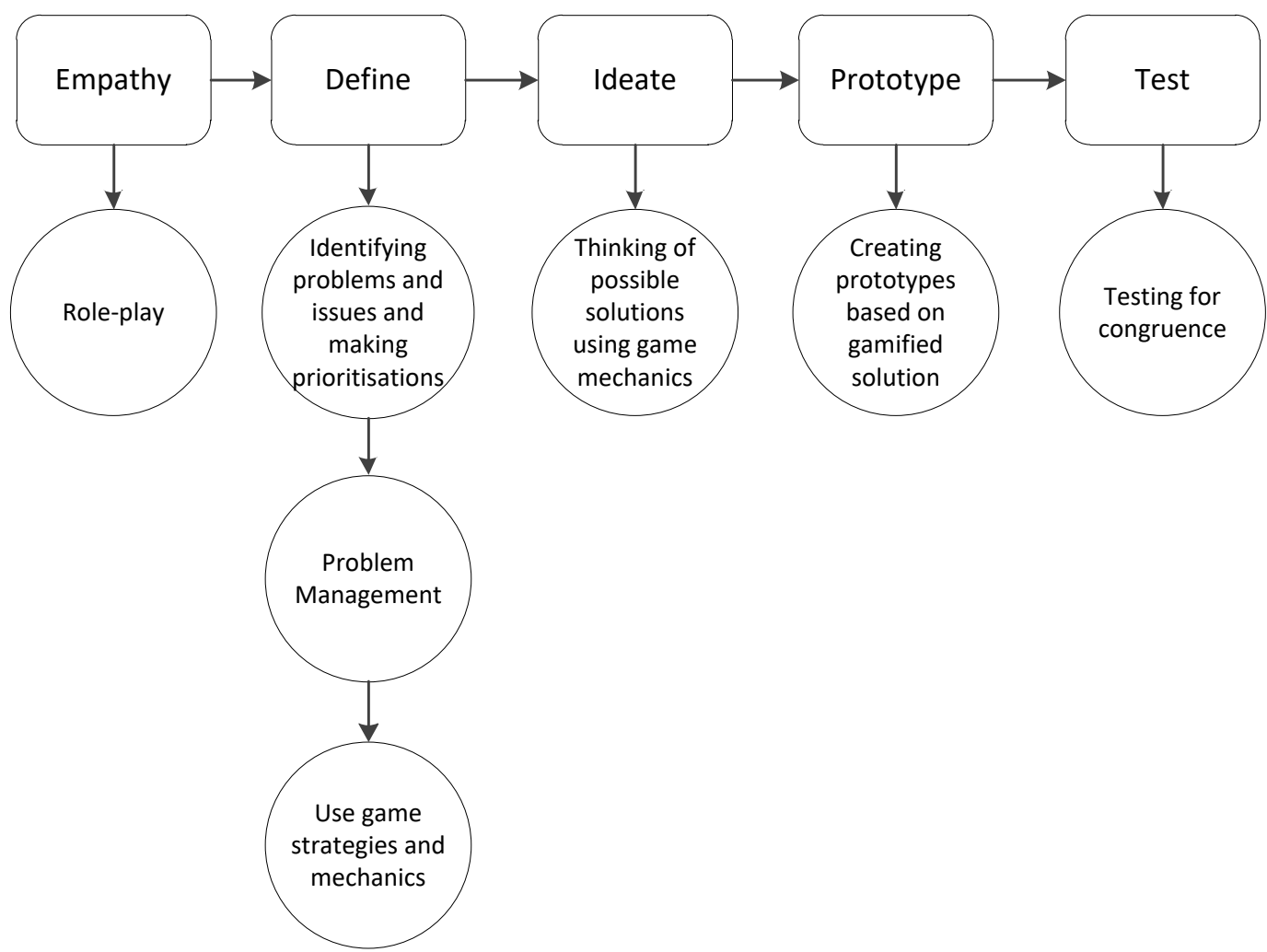

Figure 1: Game design thinking approach with play-based and game inspirations

Exercising empathy means listening without any judgemental feeling to how others explain their problems. We added in the element of role-playing to engage, inform and build understanding, build relationship and teamwork and break the ice. Once the thoughts of the problems have been collected, the team defines the problems by thinking about the insights of the problems and issues and prioritising the problems. The problem management phase uses game strategies and mechanics to achieve a common goal (e.g. in-game on how to win or how to survive). Next step is to ideate the possible solutions by selecting some strategies and the mechanics of games. From one insight and choosing from the many possible solutions, prototyping the solution (as games) commences with the same team to create a tangible output. Finally, the output is tested and shared with others in the community.

\subsection{The indigenous community and their Cultural Protocols}

The idea to create the 'play-to-engage' model came when planning for community engagement with primary schools at Telok Melano and Long Lamai in Borneo Malaysia. These two rural schools are selected for their distinct differences, geographically and culturally. From the onset, the research team recognised that as part of the protocol, the need to communicate with the village dwellers the intentions of the study first, before pursuing the project location, which was the local school. The two communities are:

- Telok Melano is a traditional fishing village separated from the mainland of Sarawak by dense wildlife reserved forest and can be reached by boats over the South China Sea or at least eight-hour hike in the forest. The majority of Telok Melano residents are ethnic Malay. Since the Kalimantan Indonesia border is merely 20 minutes' drive away, many Telok Melano residents have relatives on the Indonesian side, and several villagers also live across the border. The Telok Melano community is dependent on small scale fishing and farming for its livelihood. Only recently in late 2018, Telok Melano is connected by road to major towns in the state of Sarawak.

- Long Lamai is situated on the highlands, surrounded by dense rainforest, which is only accessible via a motorised canoe (or longboat) upriver or a few hours hike up a hill from the nearest village with a remote airfield. The Penan are the nomadic indigenous people settled in Long Lamai village, who survive by a rich culture of hunting and gathering. Long Lamai village was one of the earlier settlements, and due to its isolation geographically, the community of Long Lamai has established 
an egalitarian system, i.e. a culture of deciding community consensus. Unity and solidarity have been mostly practised values among the Penan.

In both locations, the local primary schools are established within the villages. These primary schools are SK Telok Melano and SK Long Lamei. SK Telok Melano has 39 students, and SK Long Lamei has 65 students. The local children attend primary school from the ages of seven to twelve. Typically they would enrol in secondary schools away from their villages; however, there are cases of parents reluctant to send off their children to another location, hence depriving their children to access to higher education. School teachers at these schools are mainly from other townships and other parts of the country, often unfamiliar with the culture and needs of the community in the villages.

Researchers applied the cultural protocol in both schools in Long Lamai and Telok Melano. This cultural protocol was initially discussed and developed in Long Lamai by the community and UNIMAS researchers. The cultural protocols comprises of guidelines for community and researchers and are based the United Nations Declarations of Rights of Indigenous Peoples (UNDRIP). Most notable that was used the Free, Prior and Informed Consent Principles (FPIC).

\subsection{The Model}

Using Participatory Action Research (PAR) guidelines developed by Phoa (2009), we identified the elements of the 'play-to-engage' model. Narratives from meetings and informal discussions with community members and the schools enabled a constructive consolidation of local perspectives from the community in alignment with the study's overarching goals. Community engagement is a dedicated process that requires a strong motivation to establish a mutual trust (Murphy, 2012), and such guidelines are useful to provide practical opportunities to all parties to articulate their needs. It is an important phase to determine onboarding, perceivable success and sustainability of the study within the indigenous communities.

In building the 'play-to-engage' model, we incorporated elements of action research, participatory evaluation and co-creation within the game design thinking to build a trustworthy partnership with the indigenous communities. There are two types of knowledge sets that we identified; one represents the knowledge owned and unique to the indigenous community, and one that is prescribed by the national curriculum, and presented to the children of the community through their local school. Within the communities, knowledge is shared through story-telling, demonstrations and play. Many games have been constructed to pass on knowledge of the elders to the young, and often the games are played in teams. At the local school, the national curricula are determined by mainstream philosophies and concepts, and there have been instances lamented by the children, teachers and their parents where the topic or idea presented is alien to them. In school, learning is designed by teachers to match the prescribed syllabus. The local teachers described how they occasionally use games in learning to break the usual tempo of the class. In the 'play-to-engage' model, we attempt to create a cohesive environment whereby it allows the researchers to shift from leading the study to also be a participant. Simultaneously researchers can help teachers to evolve from passive recipients into a continuum of andragogy and ultimately higher order heutagogical dimensions, where they were able to identify gaps in their learning and source methods conducive to their learning style to meet their learning needs (Smith, 2015). The playful approach is seen as an opportunity to enable co-creativity to occur deliberately, integrating knowledge from the community with those from the prescribed syllabus.

Figure 2 illustrates the co-creation approach in learning and how it fits together for productive playful learning in schools and outside school curricula. We proposed play as it is a universal language. Games could invoke positive emotional experiences (Lazarro, 2004), such as joy, optimism and pride in a person (McGonigal, 2011).

Games could also help to shift a community from negative to positive emotional experiences and to maintain a positive relationship. Gamification in school could also motivate students to participate more and change their concept as learners (Leblanc, 2006). 


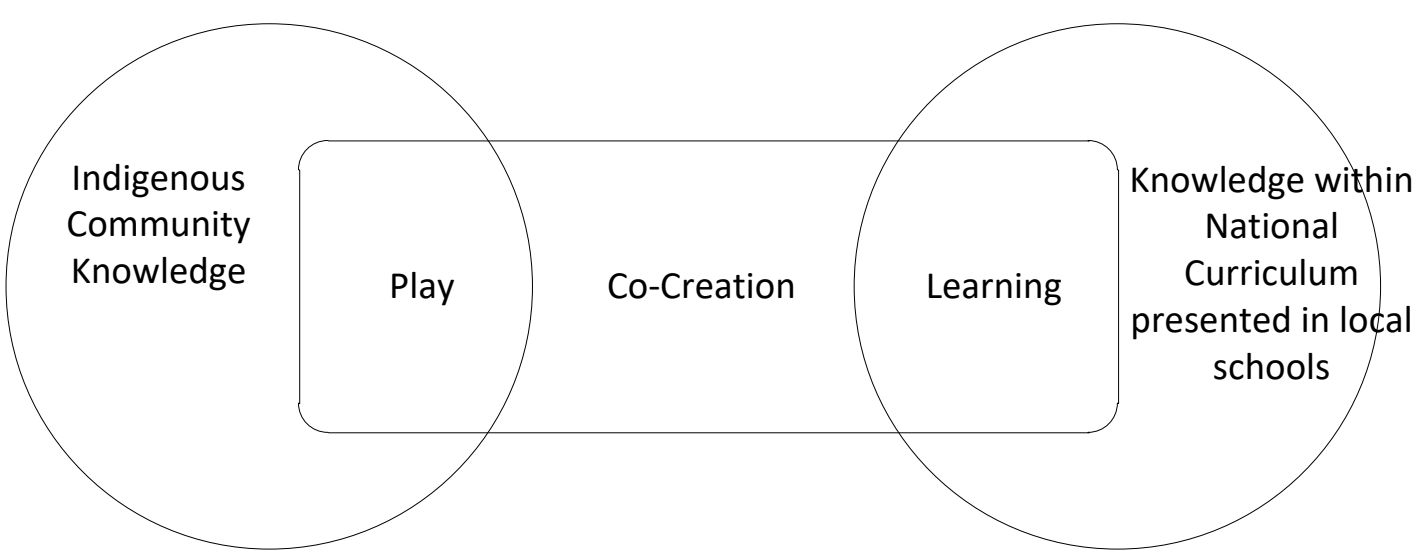

Figure 2: Co-creation in game design thinking for learning in indigenous communities in Sarawak

The idea of co-creation in game design thinking is the process of selecting ideas from the participants, in this case, they are the students and teachers, and then implementing the idea by building a prototype and testing the prototype. We also include the exploration of the creative practices, i.e. in problem-solving, and cooperative learning mechanisms, such as building trust within a group in the co-creation process.

Interestingly, in this study, we found that combining creativity, thinking and collaboration in co-creation have always been a challenge; however, in game design thinking, these processes flowed coherently. Figure 3 presents the modified and formulated 'play-to-engage' for schools. In the empathising stage, researchers are to identify schools and its community; conduct needs analysis, understand their custom, culture and protocols, share aims and purposes of the project, and get consents from the schools and community to conduct the project. A play day activity is conducted to gain access to the schools and also to identify champions. Understanding the students and teachers is vital before the define stage. Activities and specific actions are identified from the 'play-to-engage' activity day together as a team with the schools, and the students and teachers could learn from the researchers to further understand the shared purpose of the project. In the play day activities, we mixed the different core mechanics and strategies of local, commercial and traditional games into their learning. It is also known as the co-creation process. In the ideate stage, we then get the teachers and students to create and explore the remixed game-based learning content and the hybrid toolbox. Prototypes are developed for final showcase or re-remixed for further improvisation.

The model illustrates the stages to approach community onboarding. Typically in design thinking, engagement ceases to develop at the second phase, which is "Define". However, in the study, engagement with the community and school continues to flourish even after the thinking cycle is completed. The iteration of cocreativity is developed through a series of planned interventions with the teachers and the communities.

\subsection{How to Create Community Engagement in 'play-to-engage'}

We created several toolkits for engagement sessions with teachers and members of the community, to capture users' points of view. These toolkits are designed with various aims and specific instructional steps.

From the onset, we maintained the same common language to talk and discuss elements of co-creativity. For example, we listed the types of games commonly played, and we brainstormed with teachers and local community members on the mechanics and strategies of the games. The narrative in these sessions and the co-creativity element to be understood, developed and deployed in the schools. A collection of remixed games are compiled online for future use and reference (further details in Playbox1). In general, games can be used for multiple purposes, especially for breaking the ice between people and energise bored participants.

\footnotetext{
${ }^{1}$ Playbox contains the collected remixed game for learning and remixed games can be found in http://playbox.mycapsule.my
} 


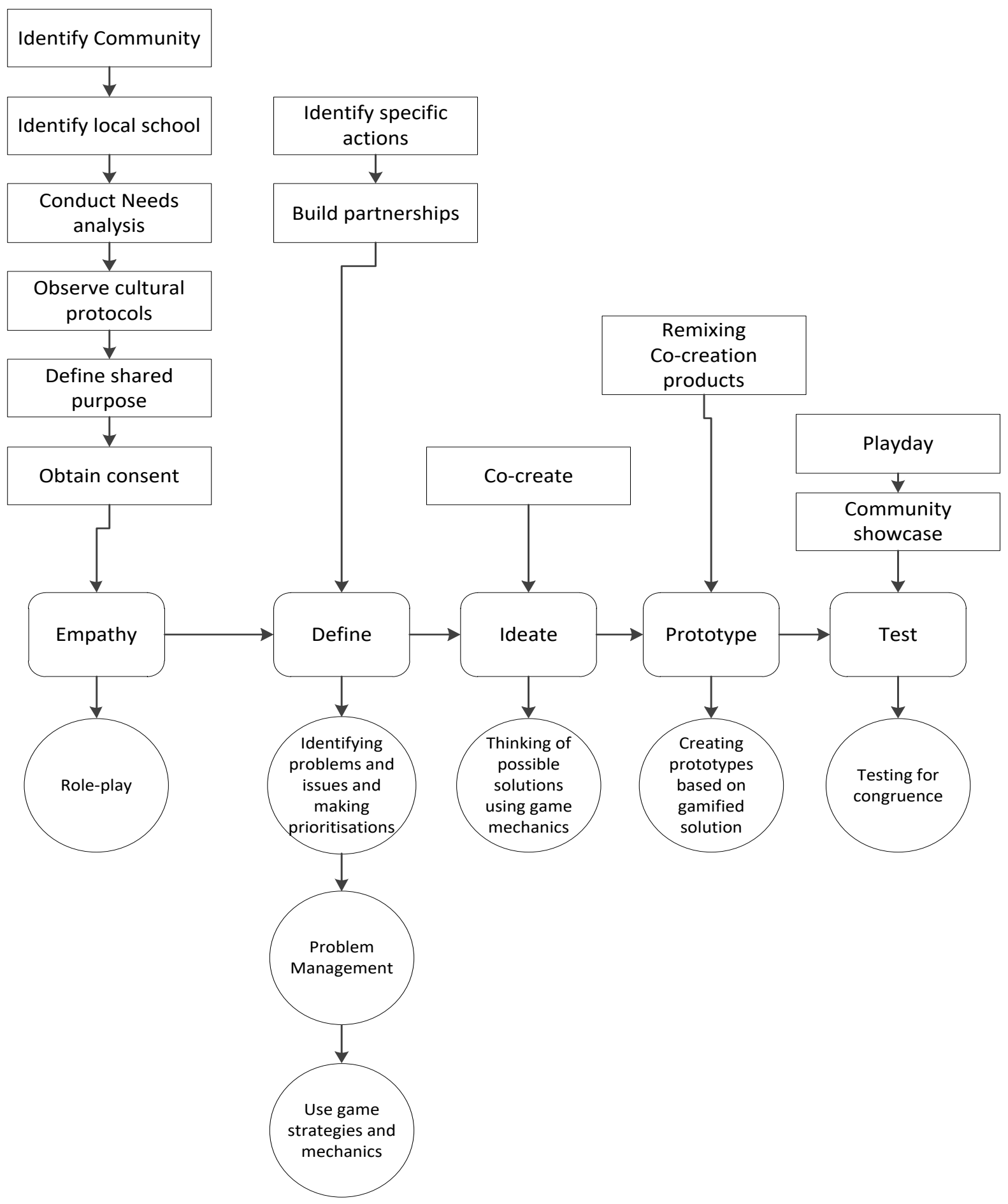

Figure 3: The 'play-to-engage' model

Remixed games add in an extra dimension to the participant engagement as these games include collaborative problem solving and learning. The 'play-to-engage' model can involve facilitators and participants in design discussions. Here, the researchers play the role as facilitators. The engagement experience is shared through the design construction process. Participants' experiences in playing games, understanding the mechanics and strategies of the games, and sharing with others, recreating new games from the different game mechanics, building prototypes and testing them with other participants, were illustrating the value of engagement. 


\section{Evaluation methods}

\subsection{Indicators of the Community Engagement in 'play-to-engage' Model}

Community engagement in schools consists of both behavioural and emotional engagement dimensions. Behaviour engagement is defined as observable behavioural characteristics based on the effort dedicated to an activity or learning and the level of achievements. Emotional engagement can be captured based on their cultural values, interest and enthusiasm. Behavioural factor (also known as participation) is an active attitude towards learning activities. Emotional factor (co-creation) is the involvements of students and teachers, and the sense of belonging to the learning community. Here, participants will invest their thoughts, mental efforts and learning strategies to achieve learning tasks by solving problems, collaborating and cooperating. These behavioural factors and emotional factors make the participatory co-creation model. In this model, we employ the 'play-to-engage' model to conduct community engagement in schools.

The indicators of the 'play-to-engage' model through narratives captured and formulated during community engagement are presented in Table 1.

Table 1: The Developed Indicators for Community Engagement in Indigenous Communities and Their Schools

\begin{tabular}{|c|c|}
\hline Indicators & Description \\
\hline Culture & 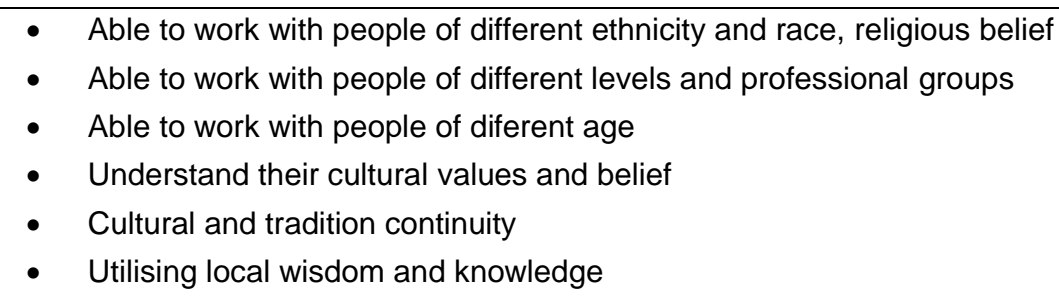 \\
\hline Learning & 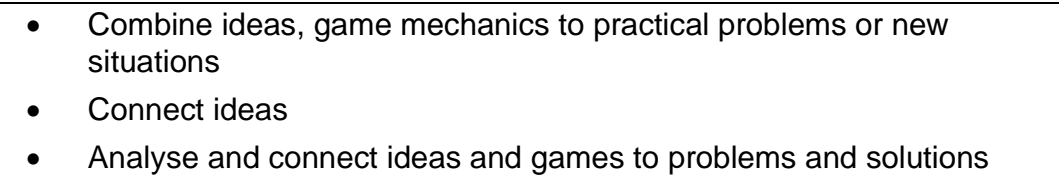 \\
\hline Participation & $\begin{array}{ll}\text { - } & \text { Interact with people } \\
\text { - } & \text { Frequently interacting with other team members } \\
\text { - } & \text { Build confidence in the group } \\
\text { - } & \text { Expression of opinions } \\
\text { - } & \text { Community activity management }\end{array}$ \\
\hline Collaboration & $\begin{array}{ll}\text { - } & \text { Work together for a common purpose to solve problems } \\
\text { - } & \text { Produce solutions }\end{array}$ \\
\hline Cooperation & $\begin{array}{ll}\text { - } & \text { Request help } \\
\text { - } & \text { Work together to solve problems } \\
\text { - } & \text { Understand someone else's views, ideas }\end{array}$ \\
\hline Questioning & $\begin{array}{ll}\text { - } & \text { Correspond to questions } \\
\text { - } & \text { Ask relevant questions }\end{array}$ \\
\hline Fun & $\begin{array}{ll}\text { - } & \text { Enjoyment } \\
\text { - } & \text { Informal experience of enjoyment of pleasure } \\
\text { - } & \text { Play activity } \\
\text { - } & \text { Creativity } \\
\end{array}$ \\
\hline $\begin{array}{l}\text { Organisation and social } \\
\text { environment }\end{array}$ & $\begin{array}{l}\text { - } \text { Encourage the team to participates and be involved socially } \\
\text { - } \quad \text { Connect with all team members } \\
\text { - } \\
\text { - } \\
\text { - }\end{array}$ \\
\hline
\end{tabular}


These engagement indicators are identified from the observation of actions, non-verbal communication, feedbacks and evidence of emotions. They were also analysed and formulated from the existing student engagement (Helme and Clarke, 2001) and the community empowerment indicators. The outcomes and feedback from the engagement sessions are recorded and categorised accordingly.

\subsection{Measurements of the Community Engagement in the Participatory Co-Creation Workshops}

It is important to highlight that community engagement is a process, as well as, an outcome (Palmer-Wackerly et al., 2014), meaning that it produces results and ideas that are emergent and co-owned by the community (schools) and therefore sustainable over time. At present, there is no way to measure the design thinking outcome (Schmiedgen et al., 2016), which we used as the basis for community engagement. However, several criteria can be used to build a measurement framework. The mix of measures that is useful, including:

- Feedback: the feedback from the participants to determine the level of satisfaction based on their testimonials after each of the workshops.

- Co-creation activities: the number of co-creation activities and participants in it.

- Remixed play tangible games and products: the number of created remixed play tangible products from the co-creation activities.

- Working culture: the impact of co-creation measured factors such as motivation, change of behaviours, team collaboration and engagement.

- Reflective measurements: questionnaires, surveys, interview internally by participants.

- Relationship and communication: is there a continuous communication between the schools and researchers during and after the project? The trustworthy partnership between the community and the researchers.

- Replicability: can this play-to-engage approach be used and implemented to other projects?

The use of the Free, Prior and Informed Consent certificate helped researchers to understand their roles and responsibilities from the start of the project. Using game design thinking, we organised remixed play activities with both the communities and their local schools. As community engagement is seen as a continuum of community involvement, the continuous engagement aims to collect local knowledge, issues and motivations from the local schools and communities.

\section{Findings and Discussions}

\subsection{Engagement with the Communities}

The aim of the engagement is to present the CreativeCulture project to the communities. The findings presented here are based on the play and games activities with communities to strengthened the researchers' partnership with the communities. The playday was run for approximately 4-5 hours together with these indigenous communities, to get people in an open, playful, and moderately risk-taking frame of mind, psychically warm them up. In addition to the activity, the research team has collect and better understand the core mechanics and strategies in their local games, and stories behind each game.

In looking at the participation during the play day activities, all the indicators in Table 1 are exemplified during the play day activity with the village head and community of elders during community engagement. The community, including the elders and the village head, organised and each of them came and participated the Playday (indicator: organisation and social environment). Both groups, the research team and the community, were learning from one another to understand the culture, community, their local games, the story behind the games, and we also challenged them to think of ways that we can use the games for learning in schools (indicator: learning, culture, questioning). There was a positive interaction and good bond during the participation (indicator: participation). We collaborated and cooperate to win the game, and to improve the strategies to winning the game (indicator: collaborate, cooperate, questioning). Everyone had a good laugh and fun during the Playday (indicator: fun).

The Playday has indeed strengthened a positive relationship between the researchers and the indigenous communities and their local school communities. 


\subsection{Indicators of Engagement in Schools}

We conducted engagement with the two rural schools to present the CreativeCulture project. We have applied participatory co-creation. In the beginning, we showcased some of the games that were remixed, created and developed by the Computer-Supported Collaborative Learning (CSCL) students from the previous activities for the teachers and students to play (details of the remixed games can be found in Mohamad et al. (2018)). The next session on different days, we conducted the 'play-to-engage' approach with the teachers and students.

The teachers also shared and discussed their concerns and interest, and these indicators correspond to the developed indicators. Each of the indicator will be further described and the findings from the engagement activites are exemplified in Table 2.

Table 2: Indicators and Findings from the Participatory Co-creation Engagement

\begin{tabular}{|c|c|}
\hline Indicators & Findings \\
\hline Culture & $\begin{array}{l}\text { I have friends of different ethnicity and religious belief. } \\
\text { I know my belief and my culture. } \\
\text { I would utilise the knowledge I learnt from my family and use it in school. } \\
\text { I want to be like my father, to be a fisherman. } \\
\text { The headmaster is also involved in the activities with the teachers and students. } \\
\text { I am able to express my concerns, issues and problems. } \\
\text { The learning aspects have included cultural traits from the community. } \\
\text { Give exposure to these rural students. }\end{array}$ \\
\hline Learning & $\begin{array}{l}\text { I try to approach the activity with a new perspective. } \\
\text { I am motived to learn when there is game. } \\
\text { I am share my ideas without being judged. } \\
\text { When I grow up, I want to be ... } \\
\text { I learn to make my own games. } \\
\text { Playing games to learn is easy. } \\
\text { I could relate what I have learnt in school. } \\
\text { Can I use games for teaching? } \\
\text { I improve my teaching? } \\
\text { I use a new approach to teach. } \\
\text { I enjoy using games to learn because I want to be smart. }\end{array}$ \\
\hline Participation & $\begin{array}{l}\text { I will try answer the questions other students ask. } \\
\text { I am more confident to speak. } \\
\text { I am more daring to act. } \\
\text { I can speak up. } \\
\text { I observed that the students have gained confidence in learning. }\end{array}$ \\
\hline Collaboration & $\begin{array}{l}\text { I try to work together with other students to solve a problem. } \\
\text { I try to find ways to win the game. } \\
\text { I work together with other students to win the game. } \\
\text { It is easy to approach to the teachers to solve problems. }\end{array}$ \\
\hline Cooperation & $\begin{array}{l}\text { I could improve my communication skills. } \\
\text { I learn to listen. } \\
\text { I would ask for help. }\end{array}$ \\
\hline Questioning & $\begin{array}{l}\text { I ask question when I do not understand. } \\
\text { I learn to ask questions. }\end{array}$ \\
\hline
\end{tabular}




\begin{tabular}{|ll|}
\hline Indicators & Findings \\
\hline Fun & I have fun playing games with other students. \\
& $\begin{array}{l}\text { It is not too stressful, and I am allowed to make mistakes. } \\
\text { Students and teachers are creative. } \\
\text { Can we do this again? }\end{array}$ \\
\hline $\begin{array}{ll}\text { Organisation and Social } \\
\text { Environment }\end{array}$ & I feel there is connection with other sudents and teachers. \\
& I belong to this community. \\
& I respect my teachers and school. \\
& I will get other students to be involved. \\
I share what I have with other students. \\
The research teams are easy going and approachable.
\end{tabular}

\subsection{Reflection on the Approach: Participatory Co-creation in Rural Schools}

Applying the participatory co-creation approach in rural schools gave us the following insights.

A major success factor in the implementation of rural projects is the process of community engagement where community leaders and members of the community, including parents and teachers become in partnerships with one another, as well as, with the researchers. It is seen that the 'play-to-engage' activities in schools have invoke positive emotional experiences, and we have built strong relationship with the schools and the communities. In addition, teachers are more motivated to create learning games that they can use in their classrooms and the students were having fun while learning.

One of the comment from the teacher after the activity - "I think this co-creation activity is tremendously helpful in brainstorming ideas to design and create game activities which are suitable for our students. Besides that, we as teachers can share those ideas in creating activities which are fun and yet meaningful. From my observation, our senior teachers, who are usually passive in contributing ideas, had eagerly participated to come up with ideas for the new games and even tested it with students. Also, I witnessed how some usually passive students in the class had become leaders in their groups by coming up with ideas and implementing them in the game creation. These playful game activities seem to trigger their passion and feelings towards knowledge, which is not normally seen in a classical classroom setting. As a teacher, I want to thank all of your team members, who came to our school and helped to share new ideas and technologies with our students and teachers as well. The CreativeCulture initiative has successfully refreshed and renewed the student's interest in gaining knowledge via game-based learning activities." - teacher from SK Long Lamei.

This comment reaffirm the importance of gameplay in engagement and indeed, it could invoke positive emotional experiences and could motivate teachers and students to participate more and change their concept as learners.

\section{Conclusion}

The need for a playful protocol to aid engagement that is sympathetic to the local context has led to the development of a 'play-to-engage' model that was inspired by game design thinking that formulates the engagement pathway and processes with the indigenous community. The approach facilitated the engagement process between the communities and researchers.

One of the main strengths of game design thinking is the element of empathy. Empathy involves observing, engaging and empathising with stakeholders to better understand their experiences, issues or problems, needs and cultural protocols or customs in a community. Indigenous peoples have unique customs, protocols, procedures, rules, and regulations that regulate their everyday interactions within and between communities and with the resources and the natural surroundings.

From the onset, the research team recognised the need to communicate with the village dwellers the intentions of the study first, before pursuing the project location, which was the local school. Acknowledging that play is universal, gameplaying were used in the initial engagement process with the community. The 
approach helped ease partnership brokering between the researchers and community members, as well as the introduction of the project to the community.

In summary, the presented novel indicators for the 'play-to-engage' method have been discussed and the qualitative results were presented. The potential venues for future works will be utilising content analysis to explore the indicators used in this method, and to measure the correlation of the indicators.

\section{Acknowledgements}

The study was funded by the Newton-Ungku Omar Fund (ref no. GL/F07/NOUF/02/2017)and Arts and Humanities Research Council UK(ref no. EP/P017037/1). The study would not have been possible without the commitment and collaboration between members of local communities, teachers and students from SK Long Lamei and SK Telok Melano, and Learning Sciences postgraduates. The study was also supported by the management and research teams at the Institute of Social Informatics and Technology Innovation, UNIMAS.

\section{References}

Arnab, S., Morini, L., Green, K., Masters, A. and Bellamy-Woods, T., 2017. We are the Game Changers: An Open Gaming Literacy Programme, International Journal of Game-Based Learning (IJGBL), Vol. 7 No. 3, pp. 51-62.

Bala, P., 2012. Needs Analysis in Developing Telecentre Among Orang Asli West Malaysia, Final Research Report.

Brodin, J., Goodwin, J., Knell, G. and Kruythoff, K., 2019. What the global 'play gap' means for our children's futures. World Economic Forum. website <https://www.weforum.org/agenda/2019/01/play-gap-hurting-childrens-skills-futures/> [Accessed 20 April 2019].

Burkett, T., 2006. So what is social design?. website <http://www.design4socialinno vation.com.au/news/so-what-socialdesign-ingrid-burkett/> [Accessed 11 May 2018].

Dickson, G., \& Green, K. L., 2001. Participatory action research: Lessons learned with Aboriginal grandmothers. Health Care for Women International 22(5), 471-82.

Haig-Brown, C., Dannenmann/Kaamatweyaashiik, K., 2002. To Be in Good Relation: The search for community. Amsterdam: International Society for Cultural Research and Activity Theory.

Hancock, T., 1997. Ecosystem Health, Ecological latrogenesis, and Sustainable Human Development, Ecohealth Perspective, Vol 3, No 4.

Helme, S., and Clarke, D., 2001. Identifying Cognitive Engagement in the Mathematics Classroom. Mathematics Education Research Journal, 13(2), pp 133-153.

Lazzaro, N., 2004. Why we play games: Four keys to more emotion without story. website $<$ http://www.xeodesign.com/xeodesign whyweplaygames.pdf> [Accessed 11 May 2018].

Leblanc, G., 2004. Enhancing Intrinsic Motivation Through the Use of a Token Economy. Essays in Education, 11(1).

Madden, B., Higgins, M., \& Korteweg, L., 2013. Role Models Can't Just Be on Posters: Remembering Barriers to Indigenous Community Engagement. Canadian Journal of Education, 36(2), 212-247.

McGonical, J., 2011. Reality is Broken: Why Games Make Us Better and How They Can Change the World. Penguin Press. New York, NY.

Mikkelsen, B., 1995. Methods for Development Work and Research. A Guide for Practitioners. London, New Delhi: Sage Publications, Thousand Oaks.

Mohamad, F., Morini, L., Arnab, S., Minoi, J., 2018. Engaging Primary Schools in Rural Malaysia with Game-based Learning: Culture, Pedagogy, Technology. ECGBL 2018.

Murphy F., 2012. Community Engagement, Organization, and Development for Public Health Practice. Springer Publishing. New York, NY.

Palmer-Wackerly, A. L., Krok, J. L., Dailey, P. M., Kight, L., \& Krieger, J. L., 2014. Community engagement as a process and an outcome of developing culturally grounded health communication interventions: An example from the DECIDE project. American Journal of Community Psychology, 53, 261-274.

Phoa, J., Bala, P., 2009. From the Kelabit Highlands to the world: Replicating the e-Bario Model. A paper presented at the National Seminar of e-Community 2009.

Schmiedgen, J., Spille L., Koppen E., Rhinow H., and Meinel. C., 2016. Measuring the Impact of Design Thinking. In H. Plattner at al. (Ed.), Design Thinking Research: Making Design Thinking Foundational (pp. 157-170). Switzerland: Springer International Publishing.

Severtson, D. J., Baumann, L. C., \& Will, J. A., 2002. A participatory assessment of environmental health concerns in an Ojibwa community. Public Health Nursing 19(1), 47-58.

Smith, S., 2015. Playing to engage: Fostering engagement for children and teachers in low socioeconomic regions through science and mathematics play-based learning (Doctor of Philosophy (College of Education)). University of Notre Dame Australia. website<https://researchonline.nd.edu.au/theses/116> [Accessed 21 September 2018].

Zaman, T., 2013. Indigenous Knowledge Governance Framework: A Holistic Model for Indigenous Knowledge Management, PhD. Universiti Malaysia Sarawak. 